\title{
A PESQUISA COLABORATIVA NA EDUCAÇÃO FÍSICA ESCOLAR
}

\author{
COLLABORATIVE RESEARCH IN SCHOOL PHYSICAL EDUCATION
}

LA INVESTIGACIÓN COLABORATIVA EN LA EDUCACIÓN FÍSICA ESCOLAR

\author{
Samara Queiroz do Nascimento Florêncio*, \\ Pierre Normando Gomes-da-Silva**
}

\section{Palavras chave:}

Metodologia.

Pesquisa qualitativa. Educação Física.
Keywords: Methodology. Qualitative Research. Physical Education.

\begin{abstract}
Resumo: O objetivo deste trabalho é analisar a contribuição da pesquisa colaborativa para a articulação entre o fazer cotidiano do professor de Educação Física ao tratar o conteúdo dança e o processo de reconhecimento e reconstrução de novos conhecimentos com rigor científico. Foi utilizada a pesquisa colaborativa com abordagem qualitativa. Foram pesquisadas 35 professoras de Educação Física e acompanhadas três em seu cotidiano escolar. A hermenêutica foi utilizada para analisar as informações coletadas a partir da narrativa de formação, seminários temáticos, grupos focais, laboratórios, sessões reflexivas e vídeo etnográfico. Reconhecemos que a pesquisa colaborativa permitiu 0 avanço no fazer ciência e nas ações pedagógicas das professoras e revelou a reflexão como elemento essencial para esta ressignificação.
\end{abstract}

Abstract: This study analyzes the contribution of collaborative research to the interconnection between Physical Education teachers' daily tasks in approaching dance as content and the process of recognition and reconstructing new knowledge with scientific rigor. It used qualitative collaborative research. A total of 35 female Physical Education teachers were surveyed and three of them were observed in their daily school life. Hermeneutics was used to analyze the information collected from formation narrative, thematic workshops, focus groups, laboratories, reflective sessions, and ethnographic video. Collaborative research allowed advancing in the practice of science and in teachers' pedagogical activities, and it revealed reflection as an essential element for that reinterpretation.

Palabras clave: Metodología. Investigación cualitativa. Educación Física.
Resumen: El objetivo de este trabajo es analizar la contribución de la investigación colaborativa para la articulación entre el quehacer cotidiano del profesor de Educación Física al tratar el contenido danza y el proceso de reconocimiento y reconstrucción de nuevos conocimientos con rigor científico. Fue utilizada la investigación colaborativa con enfoque cualitativo. Un total de 35 profesoras fueron investigadas y tres participantes de ese grupo fueron observadas en su cotidiano escolar. La hermenéutica fue utilizada para analizar las informaciones recogidas a partir de la narrativa de formación, seminarios temáticos, grupos focales, laboratorios, sesiones reflexivas y vídeo etnográfico. Reconocemos que la investigación colaborativa permitió el avance en el hacer ciencia y en las acciones pedagógicas de las profesoras, y reveló la reflexión como elemento fundamental para esta resignificación.
*Universidade de Pernambuco. Recife, PE, Brasil.

E-mail: samara.qnf@gmail.com

**Universidade Federal da Paraíba. João Pessoa, PB, Brasil.

E-mail: pierrenormandogomesdasilva@ gmail.com

Recebido em: 09-06-2016 Aprovado em: 22-01-2017

(c) (1) (3) Licence 


\section{INTRODUÇÃOO}

Discutir a temática da formação de educadores sob a perspectiva do diálogo ensinopesquisa implica criticar o modelo positivista de se fazer ciência. Modelo este que tem seus princípios epistemológicos pautados sob a égide objetivista e reprodutivista valorizando 0 saber científico em detrimento do saber popular.

Parte-se do entendimento de que o saber produzido no cotidiano escolar precisa ser reconhecido e que, ao ser elaborado, configura-se não só como um diagnóstico da prática educativa, mas, sobretudo, como procedimento de investigação científica que contribui para a confirmação e construção de novos conhecimentos.

No contexto da produção do conhecimento em que o foco é o processo de produção contextualizada, valorizam-se as formas subjetivas do saber dos sujeitos envolvidos. Todavia, essas diferentes formas não deixam de estar pautadas por um rigor metodológico. Dessa forma, acredita-se que estas pesquisas podem contribuir para a produção de um saber que é tanto científico quanto pedagógico, o que Gauthier et al. (2006) denominou de "saber da ação pedagógica".

[...] o saber experiencial dos professores a partir do momento em que se torna público e que é testado através de pesquisas realizadas em sala de aula. Os julgamentos dos professores e os motivos que lhes servem de apoio podem ser comparados, avaliados, pesados, a fim de estabelecer regras de ação que serão conhecidas e aprendidas por outros professores (GAUTHIER, et al., 2006, p.33).

Pensar a produção do conhecimento no âmbito pedagógico remete à reflexão acerca da sua cientificidade atrelada, sobretudo, à sua função social. Disso decorre a relevância em se considerar a necessidade de ruptura do pensamento positivista e de compreender a produção do conhecimento no diálogo entre ciência e sociedade. Para tanto, constitui-se um desafio às pesquisas sociais manterem um rigor metodológico, que atribua um valor científico ao saber produzido no cotidiano escolar.

Corrobora-se Pimenta (2005) ao identificar que a pesquisa colaborativa pode contribuir nesse processo de valorização do saber que emana da prática pedagógica do professor ao permitir construir o conhecimento com os professores, e não sobre eles.

Nesse sentido, a questão-problema é: como a pesquisa colaborativa contribui para a ressignificação da prática pedagógica e da produção do saber do professor de Educação Física? Assim, tem-se como objetivo analisar a contribuição da pesquisa colaborativa para a articulação entre o fazer cotidiano do professor de Educação Física ao tratar o conteúdo dança e o processo de reconhecimento e reconstrução de novos conhecimentos com rigor científico.

\section{MATERIALIZAÇÃO DA PESQUISA COLABORATIVA NO FAZER PEDAGÓGICO DE PROFESSORAS DE EDUCAÇÃO FÍSICA}

Por muito tempo o saber do professor produzido cotidianamente foi negado em detrimento do saber científico. Por outro lado, o saber científico é desprezado, dando espaço apenas aos saberes construídos na prática. Compreendemos que esses saberes estão imbricados e se complementam na ação docente, constituindo-se como parte da competência do professor. 
Sobre os saberes docentes dialoga-se com Borges (2001), Monteiro (2001) e Oliveira e Ramos (2008) ao reconhecer os escritos dos autores Tardif, Lessard e Lahaye (1991) como referência na classificação e conceituação desta área, que abrange desde a formação inicial do professor até os saberes adquiridos na prática docente. São eles: Saberes da formação profissional (das ciências da educação e da ideologia pedagógica), conjunto de saberes transmitidos pelas instituições de formação de professores; Saberes disciplinares, saberes que correspondem aos diversos campos do conhecimento, aos saberes de que dispõe a nossa sociedade, tais como se encontram hoje integrados nas universidades, sob a forma de disciplinas, são transmitidos nos cursos e departamentos universitários independentemente das faculdades de educação e dos cursos de formação de professores; Saberes curriculares, que correspondem aos discursos, objetivos, conteúdos e métodos a partir dos quais a instituição escolar categoriza e apresenta os saberes sociais por ela definidos e selecionados como modelos da cultura erudita e de formação para a cultura erudita; Saberes experienciais, baseados no trabalho cotidiano e no conhecimento de seu meio. Segundo Oliveira e Ramos (2008), esses saberes são desenvolvidos fora da instituição formadora, aproximando-se mais da realidade escolar, pois têm origem nessa prática cotidiana. Tardif (2008) considera que estes brotam da experiência e são por ela validados, incorporam a experiência individual e coletiva sob a forma de habitus e de habilidades, de saber-fazer e saber-ser. Complementamos com os saberes pessoais, advindos das experiências de vida dos professores, aqueles que antecedem sua narrativa de formação, parte de sua trajetória de vida e tornam-se elementos significativos no seu fazer pedagógico (GOMES-DA-SILVA, 2009).

Ao entender a prática pedagógica como elemento constante de construção do saber, atribuímos ao professor uma condição de pesquisador. Nessa elaboração, é indispensável o rigor metodológico para que o saber produzido possa, então, ser ressignificado nas práticas de outros professores. Nesse sentido, a pesquisa colaborativa pode contribuir, uma vez que é uma das modalidades da pesquisa-ação, cujo objeto principal é a intervenção dos professores em relação à resolução de um problema coletivo (BEZERRA, 2007).

Segundo Thiollent (1994), a pesquisa-ação define, de um lado, a exigência de conhecimento a ser produzido e, do outro lado, a sua ação, seus agentes, objetivos e obstáculos. Assim, a pesquisa colaborativa responde tanto a uma lacuna científica como a uma necessidade de ação pedagógica teorizada.

Dessa forma, aplicamos o método colaborativo com um grupo de 35 professoras de Educação Física, participantes do Programa de Formação Continuada "Dança-Educação", oferecido pela Secretaria de Educação da Prefeitura Municipal de João Pessoa. Nesse momento, foi identificado o problema coletivo, apresentado pelos sujeitos da pesquisa e coordenação do programa, que consistia na "fragilidade epistemológica da intervenção pedagógica das professoras". Para o aprofundamento da pesquisa foram selecionadas três professoras, denominadas de professoras colaboradoras (PC), a partir de Moura (2004) e André (2004), e representadas por nomes fictícios: Ayla, Emanuele e Lavínia. A escolha das três teve como critério a disponibilidade de participação em todos os processos da pesquisa. Denominamos o pesquisador como professor pesquisador (PP).

Para identificação do problema coletivo, foi utilizada a técnica da narrativa de formação, que, como uma modalidade da autobiografia, possibilita a produção do conhecimento 
pedagógico, aproximando-se, de forma efetiva, das realidades educativas e do cotidiano dos professores, pois, narrando suas trajetórias, suas construções, suas decisões, revela conteúdos e discursos pautados pelas marcas e pela influência da cultura docente (WITTIZORECKI et al., 2006). Esta característica possibilita à pesquisa colaborativa uma maior interação entre os professores e pesquisadores e a realidade investigada, uma vez que revela as atribuições de significados sobre o objeto estudado.

De acordo com Wittizorecki et al. (2006), a construção da narrativa de formação emprega o recurso de recordações-referências para compreender como nos formamos em meio a um conjunto de experiências ao longo da vida; propõe, assim, a "narração de si mesmo", a partir de questionamentos sobre o que é a formação e como essa se deu, e compreende as aprendizagens do passado como caminho para se construir as atitudes, pensamentos e ações do presente.

Para a realização da narrativa de formação, inicialmente, foi proposto um questionário com questões abertas para que as professoras pudessem expressar, por escrito, sua trajetória com a dança. Entretanto, após análise desse material, notou-se que com as informações coletadas pouco se poderia compreender da trajetória de profissionalização dessas professoras, por apresentarem relatos sucintos. Assim, tornou-se necessária a aplicação da entrevista, seguindo o mesmo roteiro de questões do questionário.

A entrevista permitiu coletar informações mais detalhadas sobre a trajetória profissional, e o texto da narrativa de formação foi realizado com cada professora. Essa técnica possibilitou que as professoras colaboradoras retomassem suas memórias e seus objetivos ao se formarem, permitindo refletir como estavam atualmente, e de forma positiva contribuiu para uma autoavaliação. Nesse momento, a reflexão é mais uma vez uma ação utilizada como meio para ressignificar 0 agir pedagógico das professoras colaboradoras.

Para o professor pesquisador, a técnica revelou aproximações das professoras colaboradoras com os saberes pessoais e da experiência e permitiu compreender a fragilidade apresentada pelo grupo quanto ao embasamento teórico.

Ao realizar esse mapeamento, foi possível direcionar o estudo para responder tanto a necessidade social do estudo (fragilidade epistemológica apresentada nas falas das professoras) quanto o aspecto científico (como o processo colaborativo contribui para esse novo agir). Assim, utilizamos outra técnica, que foi a dos seminários temáticos.

O seminário temático (ST), na pesquisa colaborativa, é uma técnica relevante para abertura do ato reflexivo com foco no saber científico. Presta-se, portanto, a apresentar, discutir, analisar, avaliar, construir ou reconstruir o conhecimento científico e pedagógico. O seminário temático (ver Quadro 1, na próxima página), nesta pesquisa, foi pensado a partir da prática da dança na Educação Física Escolar e direcionado para as 35 professoras participantes do grupo.

Após a realização dos seminários temáticos, foi notória a ampliação dos conceitos em dança-educação das professoras colaboradoras. Estes seis seminários permitiram que as professoras tivessem contato mais aprofundado com a teorização da proposta, conhecessem os conceitos e teorias que predominam no ensino da dança-educação e que refletissem sobre a realização desta proposta nas aulas de Educação Física. 
Quadro 1 - Descrição dos seminários temáticos realizados com as 35 professoras

\begin{tabular}{|c|c|c|c|c|}
\hline $\begin{array}{l}\text { Seminário } \\
\text { temático }\end{array}$ & $\begin{array}{c}\text { Duração } \\
\text { (horas) }\end{array}$ & $\begin{array}{c}\text { Professora } \\
\text { Ministrante (PM) }\end{array}$ & Tema & Objetivo \\
\hline ST1 & 13 & D. $N^{1}$ & Dança-Educação & $\begin{array}{l}\text { Compreender a proposta dança-educação } \\
\text { e seu diálogo com a Educação Física } \\
\text { Escolar. }\end{array}$ \\
\hline ST2 & 4 & L.M e N.B & Danças Populares & $\begin{array}{l}\text { Conhecer as danças da Região Centro- } \\
\text { Oeste e compreender como trabalhar com } \\
\text { a dança popular mediada pela proposta } \\
\text { Dança-Educação nas aulas de Educação } \\
\text { Física. }\end{array}$ \\
\hline ST3 & 4 & A.P & $\begin{array}{l}\text { Dança Moderna } \\
\text { e Consciência } \\
\text { Corporal }\end{array}$ & $\begin{array}{l}\text { Conhecer, experimentar e explorar as } \\
\text { habilidades motoras de caminhar, arrastar, } \\
\text { escorregar, inclinar, estender, torcer, } \\
\text { empurrar e girar, utilizando diferentes } \\
\text { bases de sustentação corporal; ampliar } \\
\text { o repertório de movimento; reconhecer } \\
\text { e perceber as possibilidades motoras } \\
\text { individuais e em grupo; e ampliar } \\
\text { possibilidades de interação com os outros } \\
\text { e com o mundo; compreender como } \\
\text { trabalhar com tema apresentado nas aulas } \\
\text { de Educação Física Escolar. }\end{array}$ \\
\hline ST4 & 4 & J.B e F & Danças Populares & $\begin{array}{l}\text { Conhecer as danças da Região Sudeste } \\
\text { e compreender como trabalhar com as } \\
\text { mesmas nas aulas de Educação Física } \\
\text { mediadas pela proposta Dança-Educação. }\end{array}$ \\
\hline ST5 & 3 & A.P & $\begin{array}{l}\text { Dança Moderna, } \\
\text { consciência } \\
\text { corporal e } \\
\text { adaptação a } \\
\text { parceiros }\end{array}$ & $\begin{array}{l}\text { Conhecer, experimentar e explorar } \\
\text { movimentos de dança individualmente } \\
\text { e depois em parceria; construir frases } \\
\text { de movimento em dupla com base na } \\
\text { exploração de gestos do silêncio e de } \\
\text { ritmos preestabelecidos; desenvolver } \\
\text { a consciência corporal através da } \\
\text { exploração de movimentos em dupla nos } \\
\text { níveis intermediário alto, médio, baixo } \\
\text { e intermediário baixo; desenvolver a } \\
\text { consciência espacial através da construção } \\
\text { de frases de movimentos em dupla; } \\
\text { desenvolver a consciência para treinar } \\
\text { as habilidades de girar, saltar e cair, } \\
\text { locomover-se e elevar; e compreender } \\
\text { como trabalhar com o tema nas aulas de } \\
\text { Educação Física. }\end{array}$ \\
\hline ST6 & 1 & L.M & Danças Populares & $\begin{array}{l}\text { Conhecer as danças da Região Norte } \\
\text { e compreender como trabalhar com as } \\
\text { mesmas nas aulas de Educação Física } \\
\text { mediadas pela proposta Dança-Educação. }\end{array}$ \\
\hline
\end{tabular}

Fonte: Próprio do autor.

Na verdade, foi bom porque eu relembrei várias coisas da minha prática. E o mais importante é categorizar nossa prática, porque a gente tem muita coisa prática, muita vivência, muita história de vida, e, às vezes, a gente olha e diz: e é isso é? Eu estava fazendo e nem sabia. $E$ então, essa historicidade e teoria dão muito mais respaldo ao nosso trabalho (LAVÍNIA, Grupo Focal 1).

1 Refere-se às iniciais dos nomes das professoras ministrantes que conduziram os seminários temáticos. 
Complementa a fala da profa Emanuele:

Agora foi que caiu a ficha. Eu estava fazendo tudo errado com meus alunos, em vez de eu estar ajudando eu estava acabando com os meninos. Então assim, você vai tendo uma consciência [...]. Eu cobrava deles sem saber o que eu estava cobrando. Agora não, eu já tenho a consciência, mesmo que eu não consiga fazer, eu sei o que eu quero, eu estou entendendo um pouquinho (EMANUELLE, Sessão Reflexiva Coletiva).

Na fala da profa Emanuele, retrata-se a crítica levantada por Gauthier (2006, p. 20) de que "é importante retomar certas ideias preconcebidas que apontam para o enorme erro de manter o ensino numa espécie de cegueira conceitual". 0 erro apresentado baseia 0 ensino em um "ofício sem saberes", em que basta conhecer o conteúdo, ter talento, bom senso, intuição, experiência ou, simplesmente, cultura para ser professor. Gauthier (2006) propõe "um ofício feito de saberes" que dialogue entre os diferentes saberes dos professores, quais sejam disciplinares, curriculares, das ciências da educação, experienciais e da ação pedagógica.

Mas, às vezes, você faz e pensa que não está fazendo. Como eu disse: meu Deus! A gente está fazendo uma coisa achando que não está correto aquilo, e na verdade está indo bem no seu desenvolvimento (AYLA, Sessão Reflexiva Coletiva $\left.{ }^{2}\right)$.

Os seminários temáticos contribuíram para a ressignificação da reflexão entre teoria/ prática. Foi necessário que as professoras refletissem sobre os diversos saberes (pessoais e experienciais - resgatados na narrativa de formação e os profissionais - reelaborados nos seminários) para poderem planejar os laboratórios e, ao refletirem sobre a prática, mediada por uma consciência teórica, puderam compreender e dar nova significação ao agir pedagógico.

Para chegar a esse denominador comum, foi utilizada a técnica do grupo focal, que, como uma técnica de coleta, se caracteriza pela mediação do entrevistador com os grupos sociais, tratando de situações específicas e desenvolvendo opiniões mais abrangentes (MINAYO, 2001; GOMES-DA-SILVA, 2009). A escolha se deu por consistir em uma técnica de coleta de informações coletivas a partir de tópicos que são fornecidos pelo pesquisador e no trabalho conjunto das professoras colaboradoras (RESSEL et al., 2008; GOMES-DASILVA, 2009).

No estudo, o grupo focal teve como objetivo principal tematizar as discussões acerca dos conteúdos em dança-educação, vistos nos seminários e sua aplicação na Educação Física Escolar. Como foram tratados três temas centrais, aconteceram três grupos focais, realizados sempre ao encerrar o trato com a temática abordada. O primeiro, ao final do ST1, tematizando a dança-educação, o segundo, após o ST5, com foco na discussão sobre o ensino da dança moderna e o trabalho com a consciência corporal, e, o terceiro, ao final do ST6, com a temática do ensino da dança popular na Educação Física.

O resultado gerou discussões entre as professoras de Educação Física, em grupo, focalizando tópicos específicos acerca do ensino da dança na Educação Física Escolar. Para Ressel et al. (2008), o grupo focal permite a formação de ideias novas e originais, geradas por

2 Reflexão que acontece ao final de cada ciclo de aulas laboratórios em colaboração com todas as professoras. 0 instrumento será apresentado, posteriormente, no decorrer do texto, seguindo a ordem de aplicação dos instrumentos na pesquisa. 
intermédio da interpretação de crenças, valores, conceitos, conflitos, confrontos e pontos de vista. As principais ideias apresentadas pelas professoras foram: 1) os conteúdos abordados acerca da dança eram possíveis de serem trabalhados nos três segmentos do ensino; 2) os métodos utilizados precisam ser planejados a partir de cada realidade; e 3) principalmente que a continuidade do trabalho é um fator preponderante para que efetivamente aconteça uma educação a partir da dança. Isso não acontece na realidade das três professoras visto a progressão de diálogos e distanciamentos com a proposta Dança-Educação (NANNI, 2008), tomados como requisitos para o planejamento e realização dos laboratórios.

Após a definição do problema coletivo e da experiência com os seminários temáticos, que correspondem, segundo BEZERRA 2007, à fase de exploração, foi dado seguimento ao método a partir das fases subsequentes apresentadas por Moura (2004), quais sejam: a) de planejamento; b) de ação; e c) de avaliação. Para a elaboração dos textos reflexivos das professoras, utilizamos quatro dessas fases, que são designadas especificamente por: a) a descrição; b) a informação; o significado; c) o confronto, questionamento que levou a esta ação; e d) a ressignificação, agir diferente.

Nesta etapa, desenvolvida em três ciclos no cotidiano escolar, foram acompanhadas as três professoras colaboradoras (PC). Tomamos como base o pensamento de BEZERRA (2007) ao desenvolver a pesquisa colaborativa no âmbito educacional. Assim, destacamos os seguintes aspectos que adaptamos em relação ao ensino da dança como conteúdo da Educação Física, são eles: a) escutar a voz das professoras colaboradoras sobre sua prática com o ensino da dança na Educação Física Escolar; b) aprimorar o confronto reflexivo das professoras ao tratar os saberes em dança na Educação Física; c) analisar as formas que as professoras enfrentam as situações a partir dos aspectos limitantes; e, d) privilegiar a competência das professoras quanto ao trato com os saberes em dança, partilhando com elas, nos seus contextos de atuação, a compreensão sobre o seu agir.

Passamos a explicar o desenvolvimento dos ciclos de ação-reflexão. Sobre a adequação dos ciclos, as professoras relataram:

Isso aqui funciona, viu? Vamos supor se a gente senta um dia para preparar aula, de duas semanas. Vai lá e faz, depois traz esses resultados. Depois a gente vai planejar em cima do que rendeu e o que não rendeu. Trabalhar o que ficou mal trabalhado. Ai vai fluindo, porque você sozinha não observa isso. Eu mesma estou besta depois que eu vi essa filmagem das minhas aulas, fiquei assim... [gesto de espanto] (Profa. Emanuelle, Sessão Reflexiva Coletiva).

Este método despertou nas professoras um olhar investigativo acerca de sua prática. Tomam-se como destaque duas observações realizadas na fala da profa. Emanuele: a primeira diz respeito à necessidade de colaboração entre as professoras, da reflexão em conjunto, por possibilitar a troca de informações; a segunda está no desenvolvimento do planejamento em ciclos, é pautada na avaliação, valorizando os aspectos qualitativos que 0 ensino-aprendizagem pode oferecer, o que influi em um ensino mais consciente de seus avanços e retrocessos, portanto de seus resultados.

Nessa perspectiva, a pesquisa contribuiu para dar um novo sentido ao fazer pedagógico dessas professoras colaboradoras, no qual se destacam a reflexão e ressignificação. Os ciclos foram desenvolvidos da seguinte forma: 
Quadro 2 - Ciclos de planejamento, ação, reflexão

\begin{tabular}{|l|l|}
\hline Fase do estudo & Método utilizado \\
\hline Fase de planejamento e ação - Reflexão da prática & \\
pedagógica no cotidiano escolar. & \\
- A informação - o que significa minha ação ao tratar o & \\
conteúdo dança na Educação Física Escolar? & Laboratórios \\
- O confronto - o que me levou a utilizar os saberes de & \\
dança dessa forma? & \\
- O que posso fazer para melhorar o desempenho das & \\
atividades em dança na Educação Física Escolar? & \\
\hline $\begin{array}{l}\text { Fase de avaliação - Avaliação das aulas e processo } \\
\text { vivenciado nas fases de planejamento e ação. }\end{array}$ & \\
- Ressignificação - como posso agir diferente? & Autorreflexão (vídeo etnográfico) \\
Ressignificação dos saberes da dança-educação na & Sessão reflexiva coletiva \\
Educação Física Escolar & \\
\hline
\end{tabular}

Fonte: Próprio do autor.

Os planos dos laboratórios foram elaborados em grupo nos seminários temáticos, 0 que possibilitou a interação e a participação de diferentes opiniões. A profa Emanuele retratou esse processo dizendo:

Esse jeito aqui que a gente teve de estudar, eu acho que mesmo que sejam três pessoas, quatro, mas que você tenha seu grupinho, prepara e faz, é diferente. Pronto eu tenho dificuldade, e você também tem, se juntar eu, você e mais uma, embora não seja todo mundo, mas a gente faz alguma coisa. E é melhor porque às vezes falta um jeito, um negócio e o outro, faz isso, dá ideia. Três cabeças pensam melhor do que uma. Isso aqui funciona, viu? (PROFESSORA EMANUELE, Sessão Reflexiva Coletiva).

Além do planejamento em grupo, o laboratório se mostrou relevante no contexto escolar por permitir o trato com a criatividade, a experimentação e a participação de um grupo de professores. Por meio da realização dos laboratórios, foi possível extrapolar o discurso vivenciado nos seminários temáticos e as ideias construídas nos grupos focais e analisar a materialização da proposta Dança-Educação (NANNI, 2002, 2008) no cotidiano escolar nas aulas de Educação Física.

O laboratório possibilitou aplicar um mesmo conteúdo, com objetivo idêntico em escolas diferentes, realidades distintas, revelando e concretizando a possibilidade do trabalho em cooperação, como muito bem afirmou a professora Emanuele acima. Entretanto, a relevância desses laboratórios está em planejar e reavaliar, refletir a ação em conjunto, dando então nova significação à prática pedagógica. A elaboração dos novos conhecimentos e afirmações concretas pode ser construída a partir do confronto e diálogo das diferentes realidades.

Foi denominada de laboratório a realização das aulas regulares pelas professoras colaboradoras, baseadas no método Dança-Educação (NANNI, 2002, 2008), que utiliza 0 laboratório como um momento privilegiado de experimentação e criação. Foram realizados um total de dez laboratórios, tematizados no quadro abaixo, planejados nos seminários temáticos. 
Quadro 3 - Descrição dos laboratórios

\begin{tabular}{|c|c|c|c|}
\hline $\begin{array}{l}\text { Professora } \\
\text { colaboradora }\end{array}$ & $\begin{array}{l}\text { Ano } \\
\text { escolar }\end{array}$ & Laboratório & Tema abordado \\
\hline \multirow{4}{*}{ Ayla } & \multirow{4}{*}{$4^{\circ}$ ano } & L1 & Consciência corporal (Dança moderna) \\
\hline & & L2 & Consciência corporal e adaptação a parceiros (Dança moderna) \\
\hline & & L3 & Dança popular \\
\hline & & L4 & Dança popular \\
\hline \multirow{3}{*}{ Emanuelle } & \multirow{3}{*}{ 9o ano } & L1 & Consciência corporal (Dança moderna) \\
\hline & & L2 & Consciência corporal (Dança moderna) \\
\hline & & L3 & Dança popular \\
\hline \multirow{3}{*}{ Lavínia } & \multirow{3}{*}{$5^{\circ}$ ano } & L1 & Consciência corporal (Dança moderna) \\
\hline & & L2 & Consciência corporal e adaptação a parceiros (Dança moderna) \\
\hline & & L3 & Dança popular \\
\hline
\end{tabular}

Fonte: Próprio do autor.

Todos os laboratórios foram registrados pelos vídeos etnográficos ${ }^{3}$ e realizados de acordo com a observação direta, seguindo um roteiro (Quadro 4) com registro em um diário de campo. A primeira utilidade desta técnica na presente pesquisa foi servir as professoras colaboradoras como um registro filmográfico dos acontecidos da aula-laboratório, como recurso de ampliação da visão de sua própria ação pedagógica, ao oferecer o método dança-educação e os diferentes modos de reações dos alunos ao vivenciarem esse conteúdo. A técnica ampliou a possibilidade de fidedignidade no momento da autorreflexão das professoras colaboradoras, por permitir que elas retomassem a memória do vivido nas aulas, ampliando suas informações, agora como espectadoras de suas próprias ações.

Tomamos o cuidado de realizar inicialmente um processo de aproximação com as turmas, por meio do diálogo informal, e a presença constante da câmera, criando assim um sentimento de pertencimento entre os sujeitos envolvidos no grupo, favorecendo a naturalidade das ações e intervenções pretendidas.

Quadro 4 - Roteiro de observação direta

\begin{tabular}{|c|c|}
\hline DIMENSÃO & ASPECTO OBSERVADO \\
\hline $\begin{array}{l}\text { Dimensão de } \\
\text { instrução }\end{array}$ & $\begin{array}{l}\text { - Atenção e concentração dos alunos durante a transmissão das informações } \\
\text { - Respostas do professor às dúvidas dos alunos } \\
\text { - Tempo despendido para as informações }\end{array}$ \\
\hline $\begin{array}{l}\text { Dimensão da } \\
\text { organização }\end{array}$ & $\begin{array}{l}\text { - Supervisão da participação nas atividades dos alunos (criação, apresentação, argumentação, } \\
\text { espontaneidade) } \\
\text { - Manutenção do ritmo e dinamicidade da aula (música, atividades, atenção) } \\
\text { - Percepção dos alunos quanto a dificuldades e facilidades na aprendizagem } \\
\text { - Atenção quanto aos gêneros } \\
\text {-Participação dos alunos nos momentos de planejamento e desenvolvimento das atividades }\end{array}$ \\
\hline $\begin{array}{l}\text { Dimensão de } \\
\text { planejamento }\end{array}$ & $\begin{array}{l}\text { - Execução do plano de aula } \\
\text { - Resultados dos objetivos } \\
\text { - Adequação dos conteúdos aos interesses dos alunos, adequação à faixa etária e à sequência } \\
\text { - Atenção quanto à avaliação das aulas } \\
\text { - Métodos adequados }\end{array}$ \\
\hline
\end{tabular}

Fonte: (Adaptação de ONOFRE, 1995).

30 vídeo etnográfico tem a função de registrar e narrar um acontecido ou história, pode ser apresentado sob a forma de documentários por meio de diferentes técnicas de captações e edições das imagens, ou utilizados na íntegra para análise da pesquisa. Esta técnica tem funções relevantes que auxiliam no desenvolvimento da pesquisa colaborativa. Ver (GOMES-DA-SILVA, 2009). 
Foram realizados dez vídeos referentes aos laboratórios. Segundo Gomes-da-Silva (2009), esses vídeos possibilitam que as professoras tenham uma visão ampliada de sua prática e se vejam atuando, permitindo refletir sobre suas ações.

Segundo as professoras colaboradoras, o vídeo contribuiu para a avaliação tanto dos alunos como da reflexão de sua própria prática pedagógica. A professora colaboradora Ayla afirma que: "Por isso, é bom a gente filmar, porque a gente sempre vê o que a gente pode melhorar" (AYLA, Sessão Reflexiva do L4). Prof̣̂a Emanuele também diz que: "Você sozinha não observa isso. Eu mesma estou besta depois que eu vi essa filmagem da minha aula" (PROFª EMANUELE, Sessão Reflexiva Coletiva).

A fala das professoras retrata a importância da filmagem como mecanismo de avaliação do processo de ensino-aprendizagem. Foram disponibilizados os vídeos para que as professoras pudessem assisti-los, em cada laboratório, e realizassem a reflexão individual; além de permitir que as outras professoras constatassem ou ampliassem o olhar acerca da aula ministrada e avaliada.

Permeada pelo diálogo, a reflexão possibilita aos professores "a apreciação de novas organizações discursivas que lhes permitam descrever e avaliar suas práticas pedagógicas na interação com o outro" (BEZERRA, 2007, p.78). A sessão reflexiva foi pensada como um momento relevante em que as professoras de Educação Física puderam refletir e avaliar, de forma crítica, seus laboratórios pensados sob a perspectiva da Educação Física, elaborando, em interação, as falhas e acertos dessa proposta de ensino.

As sessões reflexivas foram realizadas em dois momentos, baseados em Ibiapina (2004 apud BEZERRA, 2007), a reflexão intrapessoal e a reflexão interpessoal, descritas a seguir:

- reflexão intrapessoal ou autorreflexão, realizada individualmente pelas professoras ao refletirem sobre a sua prática no laboratório, a partir da filmagem do laboratório. As autorreflexões permitiram que as professoras avaliassem cada laboratório, contribuindo para o planejamento do laboratório seguinte, baseando-se nas falhas analisadas e nos resultados obtidos. Essa reflexão contribuiu para se pensar em uma avaliação qualitativa, privilegiando não somente os números, mas o conhecimento produzido no processo.

- reflexão interpessoal ou coletiva, que se realizou ao final de todos os laboratórios entre as três professoras colaboradoras e a professora pesquisadora. Essa sessão reflexiva permitiu que as professoras avaliassem, de maneira mais geral, todo o processo vivenciado, identificando, de forma positiva ou negativa, a experiência com a proposta dança-educação nas aulas de Educação Física.

Essas sessões reflexivas foram apresentadas nas falas das professoras colaboradoras como um novo significado no agir pedagógico, uma vez que todo o processo de realização da pesquisa sem esse momento estaria fadado ao praticismo inconsciente citado nas narrativas de formação.

Assim, entendemos que a pesquisa colaborativa permitiu não apenas investigar os problemas educativos na escola ou pesquisar sobre a atuação das professoras, mas, também, em colaboração com elas, refletimos sobre uma proposta que foi ressignificada a partir do ato reflexivo. 
Outro elemento confirmado foi o auxílio dado ao contexto da escola com as repercussões do produto da pesquisa, uma vez que foi construído coletivamente, ao longo do processo, trazendo avanços para o conjunto dos atores envolvidos. Assim, é necessário que a pesquisa colaborativa atenda a demandas, tratando não apenas o grupo investigado, mas o contexto social no qual está inserido (MOURA, 2004; PIMENTA, 2005).

Autores como Villani, Freitas e Brasilis (2009) já mostram a relação entre o ensinar e o fazer ciência. Eles analisam o caso de uma professora que investiga sua própria prática docente, avaliando este diálogo entre a pesquisa e a docência. Segundo esses autores, o desenvolvimento da pesquisa e da docência avançou de maneira colaborativa graças ao esforço e à vontade persistente da professora pesquisada em utilizar uma metodologia de pesquisa capaz de incorporar tanto aspectos objetivos como subjetivos, referentes à sua prática docente. Gomes-da-Silva (2009) e Martiny e Gomes-da-Silva (2011) vêm utilizando modo semelhante, e mostram resultados favoráveis em suas pesquisas no campo educacional da Educação Física.

Moura (2004) e Pimenta (2005) compreendem a relevância da pesquisa colaborativa pelo seu caráter positivo de parceria entre os saberes científicos e os saberes da experiência. Esta interação entre estes dois saberes gera, segundo Giovani (1998), oportunidades de exercício de práticas inovadoras e o desenvolvimento de profissionais reflexivos em educação, especificadamente na Educação Física.

A pesquisa colaborativa se procede, principalmente, por seu caráter de reflexão, realizado em interação sobre a situação atual do objeto estudado e, sobretudo, sobre as ações que são reconstruídas ao longo da pesquisa. Como afirma Tinôco (2007), é necessário que 0 diálogo permeie toda a ação reflexiva. Essas reflexões se tornam discursos ${ }^{4}$ ao serem expressas por meio da linguagem verbal, gerando um saber que é individual e coletivo.

\section{CONSIDERAÇÕES FINAIS}

Considera-se a pesquisa colaborativa uma possibilidade na construção dos saberes em pesquisas sociais, e especificamente educacionais, uma vez que traz subsídios para uma prática de pesquisa no cotidiano escolar. Além de permitir o avanço no fazer ciência nessa área, a pesquisa colaborativa traz resultados significativos para se pensar uma prática pedagógica mais reflexiva, mediada por professores pesquisadores.

Nesta pesquisa, o método colaborativo possibilitou o diálogo entre as professoras e suas diferentes realidades educacionais, ofertando a troca de informação e, consequentemente, diminuição das fragilidades quanto aos embasamentos teóricos. A prática da reflexão foi mencionada como elemento essencial para a ressignificação do ato pedagógico, destacado nas técnicas "narrativa de formação", "grupos focais" e, principalmente, nas "sessões reflexivas". Este modelo de ensino-pesquisa contribuiu para se pensar mais efetivamente sobre as qualidades do processo de ensino-aprendizagem.

O estudo também respondeu acerca da necessidade de formação de professor pesquisador, na medida em que as professoras, em sua experiência com o método colaborativo,

4 Para análise dos discursos utilizamos a hermenêutica, entretanto não discorreremos neste texto sobre esta técnica, por compreender que outras possibilidades de análise da pesquisa social podem ser utilizadas pelo pesquisador. Assim, deixamos apenas a indicação deste método, que deverá ser adequado a cada objetivo de pesquisa. 
contribuíram para a melhoria do trato com o saber em dança-educação na Educação Física. Elas também responderam de forma efetiva para o desenvolvimento da ciência, no que concerne à construção de saberes da ação pedagógica que poderá ser utilizado por outros professores.

Sugere-se que novas pesquisas sejam realizadas, ampliando a experiência com outros conteúdos da Educação Física, contribuindo efetivamente para a formação de professores mais críticos e reflexivos.

\section{REFERÊNCIAS}

ANDRÉ, Marli Elisa Dalmazo Afonso. Etnografia da prática escolar. 11. ed. Campinas: Papirus, 2004.

BEZERRA, Elizabeth Jatobá. Educar para a solidariedade: uma perspectiva para a educação física escolar. 2007, 345f. Tese (Doutorado em Educação) - Universidade Federal do Rio Grande do Norte, Natal, 2007.

BORGES, Cecília. Saberes docentes: diferentes tipologias e classificações de um campo de pesquisa. Educação \& Sociedade, v. 22, n. 74, p. 59-76, 2001.

GAUTHIER, Clermont et al. Por uma teoria da pedagogia: pesquisas contemporâneas sobre o saber docente. 2.ed. ljuí: Editora Unijuí, 2006.

GIOVANI, Luciana Maria. Do professor informante ao professor parceiro: Reflexões sobre o papel da universidade para o desenvolvimento profissional de professores e as mudanças na escola. Caderno CEDES, v. 19, n. 44, p. 46-58, 1998.

GOMES-DA-SILVA, Pierre Normando. Prática de ensino em Educação Física: por uma formação do professor-pesquisador. In: HERMIDA, J. F (Org.). Educação física: conhecimento e saber escolar. João Pessoa: Editora Universitária da UFPB, 2009. p. 103-128.

MARTINY, Luis Eugênio; GOMES-DA-SILVA, Pierre Normando. "O que eu transformaria? Muita coisa!": Os saberes e os não saberes docentes presentes no estágio supervisionado em educação física. Revista da Educação Física/UEM, v. 22, n. 4, p. 569-581, 4. Trim, 2011.

MONTEIRO, Ana Maria Ferreira da Costa. Professores: entre saberes e práticas. Educação \& Sociedade, v. 22, n. 74, p. 121-142, 2001.

MOURA, Maria da Glória Carvalho. Pesquisa colaborativa e a formação continuada do professor de educação de jovens e adultos: uma reflexão necessária. In: ENCONTRO DE PESQUISA EM EDUCAÇÃO, 3., CONGRESSO INTERNACIONAL DE EDUCAÇÃO DA UFPI, 2., 2004, Teresina. Anais... Disponível em: <http://leg.ufpi.br/subsiteFiles/ppged/arquivos/files/eventos/evento2004/GT.1/ GT1 3 2004.pdf >. Acesso em: 05.11.2016.

MINAYO, Maria Cecília de Souza (Org.). Pesquisa social: teoria, método e criatividade. 18. ed. Petrópolis: Vozes, 2001.

NANNI, Dionísia. Dança educação: princípios, métodos e técnicas. 4. ed. Rio de Janeiro: Sprint, 2002.

NANNI, Dionísia. Dança educação: pré-escola à universidade. 5. ed. Rio de Janeiro: Sprint, 2008. 
OLIVEIRA, Ana Carolina Santana de; RAMOS, Glauco Nunes Souto. Construindo saberes pela formação e prática profissionais de uma professora de Educação Física do ensino médio. Motriz, v. 14 n. 3, p. 252-259, jul./set. 2008.

ONOFRE, Marcos. Prioridades de formação didática em educação física. Boletim da Sociedade Portuguesa de Educação Física, n. 12, p.75-97, 1995.

RESSEL, Lúcia Beatriz et al. O uso do grupo focal em pesquisa qualitativa. Texto contexto enfermagem, v. 17, n. 4, p. 779-786, out./dez. 2008.

PIMENTA, Selma Garrido. Pesquisa-ação crítico-colaborativa: construindo seu significado a partir de experiências com a formação docente. Educação e Pesquisa, v. 31, n. 3, p. 521-539, set./dez. 2005.

TARDIF, Maurice; LESSARD, Claude; LAHAYE, Louise. Os professores face ao saber: esboço de uma problemática do saber docente. Teoria \& Educação, n. 4, p.215-233, 1991.

TARDIF, Maurice. Saberes docentes e formação profissional. 9. ed. Petropólis, RJ: Vozes, 2008.

THIOLLENT, Michel. Metodologia da pesquisa-ação nas organizações. 2. ed. Cortez: São Paulo, 1994.

VILLANI, Alberto; FREITAS, Denise de; BRASILIS, Rosa. Professor Pesquisador: O caso Rosa.

Ciência \& Educação, v. 15, n. 3, p. 479-496, 2009.

WITTIZORECKI, Elisandro Schultz et al. Pesquisar exige interrogar-se: A narrativa como estratégia de pesquisa e de formação do(a) pesquisador(a). Movimento, v. 12, n. 2, p. 9-33, maio/ago. 2006. 
Apoio financeiro:

Universidade Federal da Paraíba e bolsa Reuni. 